\title{
The use of involuntary treatment among older adults with cognitive impairment receiving nursing care at home
}

\author{
Citation for published version (APA):
}

Moermans, V. R. A., Bleijlevens, M. H. C., Verbeek, H., Tan, F. E. S., Milisen, K., \& Hamers, J. P. H. (2018). The use of involuntary treatment among older adults with cognitive impairment receiving nursing care at home: A cross-sectional study. International Journal of Nursing Studies, 88, 135-142. https://doi.org/10.1016/j.ijnurstu.2018.09.004

\section{Document status and date: \\ Published: 01/12/2018}

DOI:

10.1016/j.ijnurstu.2018.09.004

\section{Document Version:}

Publisher's PDF, also known as Version of record

\section{Document license:}

Taverne

\section{Please check the document version of this publication:}

- A submitted manuscript is the version of the article upon submission and before peer-review. There can be important differences between the submitted version and the official published version of record.

People interested in the research are advised to contact the author for the final version of the publication, or visit the DOI to the publisher's website.

- The final author version and the galley proof are versions of the publication after peer review.

- The final published version features the final layout of the paper including the volume, issue and page numbers.

Link to publication

\footnotetext{
General rights rights.

- You may freely distribute the URL identifying the publication in the public portal. please follow below link for the End User Agreement:

www.umlib.nl/taverne-license

Take down policy

If you believe that this document breaches copyright please contact us at:

repository@maastrichtuniversity.nl

providing details and we will investigate your claim.
}

Copyright and moral rights for the publications made accessible in the public portal are retained by the authors and/or other copyright owners and it is a condition of accessing publications that users recognise and abide by the legal requirements associated with these

- Users may download and print one copy of any publication from the public portal for the purpose of private study or research.

- You may not further distribute the material or use it for any profit-making activity or commercial gain

If the publication is distributed under the terms of Article $25 f a$ of the Dutch Copyright Act, indicated by the "Taverne" license above, 


\title{
The use of involuntary treatment among older adults with cognitive impairment receiving nursing care at home: A cross-sectional study
}

\author{
Vincent R.A. Moermans ${ }^{\mathrm{a}, \mathrm{b}, *}$, Michel H.C. Bleijlevens ${ }^{\mathrm{a}}$, Hilde Verbeek ${ }^{\mathrm{a}}$, Frans E.S. Tan ${ }^{\mathrm{c}}$, \\ Koen Milisen ${ }^{\text {d,e }}$, Jan P.H. Hamers ${ }^{\mathrm{a}}$ \\ a Department of Health Services Research, School Care and Public Health Research Institute (CAPHRI), Faculty of Health Medicine and Lifesciences, Maastricht University, \\ Maastricht, The Netherlands \\ ${ }^{\mathrm{b}}$ Department of Nursing, White Yellow Cross Limburg, Genk, Belgium \\ ${ }^{\mathrm{c}}$ Department Methodology \& Statistics, School CAPHRI, Faculty of Health, Medicine and Lifesciences, Maastricht University, Maastricht, The Netherlands \\ d Department of Public Health and Primary Care, AccentVV, KU Leuven, Leuven, Belgium \\ e Department of Internal Medicine, Division of Geriatric Medicine, University Hospitals Leuven, Leuven, Belgium
}

\section{A R T I C L E I N F O}

\section{Keywords:}

Caregivers

Cognitive dysfunction

Cross-sectional studies

Home nursing

Involuntary treatment

Older adults

\begin{abstract}
A B S T R A C T
Background: Respect for inherent dignity and individual autonomy is a basic principle in health care. However, several studies indicate that care-dependent older adults with a cognitive impairment, receiving nursing care at home, are at risk of care without their consent, referred to as 'involuntary treatment'. This includes the application of physical restraints (e.g. measures to prevent leaving bed or chair), psychotropic drugs (e.g. antidepressants, sedatives) and non-consensual care (e.g. forced hygiene, hiding medication). Research about involuntary treatment is scarce and only recently first studies have been conducted.

Objective: To investigate 1) the prevalence of involuntary treatment, 2) associated factors and 3) who requests and applies their use among older adults with cognitive impairment receiving nursing care at home.

Design: Cross- sectional study.

Setting: Homes of older adults receiving nursing care from district nurses in the eastern part of Belgium.

Participants: Data were collected from 1194 randomly selected older adults with cognitive impairments receiving nursing care at home (mean age $83 ; 67 \%$ female).

Method: District nurses completed an online questionnaire for each selected older adult in their caseload. Involuntary treatment was measured using a questionnaire identifying use of physical restraints, psychotropic medication and non-consensual care. In addition who requests involuntary treatment and who applies it was examined. Older adults sociodemographic characteristics, diagnosis of dementia, activities of daily living (ADL), cognitive status and informal caregiver burden were assessed.

Results: Involuntary treatment was used in 52\% (95\%; CI 49-55) of the total sample. Non-consensual care was most often used (73\%; 95\% CI 70-77), followed by psychotropic drugs (43\%; 95\% CI 39-47) and physical restraints (38\%; 95\% CI 35-42). The use of involuntary treatment was associated with dependency for activities of daily life (OR 1.50; 95\% CI 1.33-1.69), cognitive impairment (1.39; 95\% CI 1.25-1.55), informal caregiver burden (OR 1.05; 95\% CI 1.01-1.10) and aging (OR 0.97; 95\% CI 0.95-0.99). Informal caregivers (71\%), followed by general practitioners $(47 \%)$ most frequently requested the use of involuntary treatment, and nurses (81\%) mostly applied it.

Conclusion: In Belgium, involuntary treatment is often used in older adults with a cognitive impairment receiving nursing care at home. The implication of this study for clinical practice is that it confirms the need to develop an approach to prevent and reduce it. Further research is needed to plan and develop such an approach, in order to prevent and reduce the use of involuntary treatment.
\end{abstract}

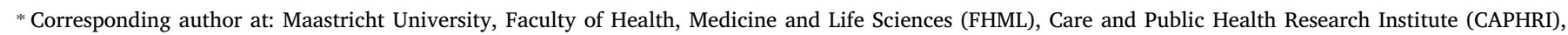
Department of Health Services Research, Duboisdomein 30, 6229 GT, Maastricht, The Netherlands.

E-mail addresses: v.moermans@maastrichtuniversity.nl, @Vincent_Moerman (V.R.A. Moermans). 


\section{What is already known about the topic?}

- In Western countries the risk of involuntary treatment is growing, due to demographic and socio-economic evolutions.

- The use of involuntary treatment has a negative impact on the quality of life of older adults.

- Research about the use of involuntary treatment is scarce and recent in the field of home care.

\section{What this paper adds}

- The results of our study showed that involuntary treatment is often used in older adults receiving nursing care at home, in Belgium.

- Our study confirmed that the use of involuntary treatment is strongly associated with higher ADL-dependency and poorer cognition.

- We identified that informal caregivers often request involuntary treatment. In addition, the general practitioner is closely involved in its request. Furthermore, we found that district nurses most frequently apply involuntary treatment.

- This study confirmed the need for developing an approach to prevent and reduce the use of involuntary treatment.

\section{Introduction}

Respect for inherent dignity and individual autonomy is a basic principle in health care. This principle justifies the moral rule that health professionals should provide help based on the patient's consent (Brodtkorb et al., 2015). Therefore, a patient should have a voice in the care he or she receives: 'no decision about me without me' (JosephWilliams et al., 2014). However, several studies indicate that older care-dependent adults with a cognitive impairment, in both nursing homes and home care, are at risk of receiving care without their consent (Beerens et al., 2014; Gjerberg et al., 2013; Hamers, 2005; Hamers et al., 2016; Scheepmans et al., 2017a). Several definitions are used to describe this kind of care: coercion care (Gjerberg et al., 2013), restraint (Scheepmans et al., 2017a) or involuntary treatment (Hamers et al., 2016). For this study, the term 'involuntary' treatment is used. Involuntary treatment is defined as treatment that professional and informal caregivers provide without the consent of the person receiving the treatment and or to which this persons resists (Hamers et al., 2016). The application and interpretation of involuntary treatment vary from country to country (Wickremsinhe, 2018). In the Netherlands, as well as in other West- European countries, regulations to prevent and reduce involuntary treatment are being developed (Hamers et al., 2016). These regulations, are based on the principle that no treatment may be provided without the consent of the person receiving it (2018). Furthermore, these regulations state that in some conditions involuntary treatment can be applied, but only if a multi-disciplinary step-by-step plan shows that there is no other alternative. Before applying the following measures, physical restraints, psychotropic medication and locking up, this step-by-step plan must be followed regardless of consent, because they are hurtful and greatly restrict the freedom of older adults. For this study, the definition of involuntary treatment is operationalized as the application of: 1) Physical restraints, defined as any action or procedure that prevents a person's free body movement to a position of choice and/or normal access to his/her body by the use of any method that is attached or adjacent to a person's body and that he/ she cannot control or remove easily (Bleijlevens et al., 2016); 2) Psychotropic medication, defined as substances that act directly on the central nervous system, affecting mood, cognition and behaviour (Voyer et al., 2004); 3) and Non-consensual care, defined as any type of care that limits the organization of a person's own life and to which a person resists to (e.g. locking in a room, use of electronic surveillance, force or pressure in activities of daily living (ADL) (Hamers et al., 2016; Gastmans and Milisen, 2006). Involuntary treatment has a negative impact on the quality of life of those who are subjected to it. For older adults, involuntary treatment increases the risk of death, falls and serious injury, feeling a loss of dignity, lower self-respect, loss of personal autonomy and feelings of imprisonment, cognitive impairment, ADLdependency and hospitalizations (Beerens et al., 2014; Gastmans and Milisen, 2006; Hofmann and Hahn, 2014; Voyer et al., 2004). Additionally, involuntary treatment is also positively associated with informal caregiver burden (Hamers et al., 2016). For the nursing staff, the request or use of measures of involuntary treatment could lead to burnout and attrition, because they are confronted with an ethical dilemma of freedom versus safety (Pijl-Zieber et al., 2008; Scheepmans et al., 2014). The reasons why older adults receive involuntary treatment can be various but include the respite of informal caregivers, postpone an admission in a nursing home (Scheepmans et al., 2017a) or for safety reasons (e.g. to prevent falls, wandering or aggressive behaviour). Caregivers do not always have sufficient knowledge about appropriate safety interventions or who to apply them. As a result safety measures (e.g. sedatives) could be incorrectly applied, applied for too long or applied for the wrong reasons (Lach and Chang, 2007; Kurata and Ojima, 2014). Furthermore, evidence that home safety interventions are effective to prevent falls are inconclusive for adults with cognitive impairment living at home (Stubbs et al., 2015). For these reasons, the emphasis of the concept involuntary treatment in our study lies on its inappropriateness rather than the lack of the consent of the older adult. It is therefore important that, before involuntary treatment is applied, this is thoroughly discussed with all caregivers involved, so that recommendations can be proposed to prevent and reduce it.

In the field of home care, research about involuntary treatment is scarce and only recently first studies have been conducted (Beerens et al., 2014; Hamers et al., 2016; Scheepmans et al., 2017a). There is only one study investigating the prevalence of involuntary treatment among cognitive impaired older adults at home (Hamers et al., 2016). The studies of Beerens et al. (2014) and Scheepmans et al. (2017a) focus on the prevalence of certain aspects of involuntary treatment such as physical restraint or psychotropic medication. The study Hamers et al. (2016) showed that in a Dutch sample of 837 persons with cognitive impairment receiving professional care at home, 39\% received involuntary treatment. If involuntary treatment was applied, measures of non-consensual care (79\%) was most commonly used on older adults, followed by psychotropic medication (41\%) and physical restraints (7\%). Caregiver burden, greater ADL dependency, poorer cognitive ability, living alone and having a formal diagnosis of dementia are factors that were strongly associated with involuntary treatment. In Western countries, the prevalence of these factors is growing, due to demographic and socio-economic evolutions (Etters et al., 2008; Koller et al., 2014). For these reasons the risk of the application of involuntary treatment will increase in the coming years. Therefore, it is necessary to gain more insight into its application, so we can prevent and reduce it. Because research about involuntary treatment is recent and scarce (Hamers et al., 2016), we do not have enough insight to draw conclusions about its prevalence, which factors are associated with its application and who requests and uses it. To generalize previous research, it is necessary to gain an insight into the use of involuntary treatment in other countries. These insights will help caregivers and researchers to develop interventions to prevent and reduce its use.

The objective of this study was to gain an insight into the use of involuntary treatment among older adults with cognitive impairment receiving nursing care at home, in Belgium. The following research questions will be answered: 1) What is the prevalence of the use of involuntary treatment? 2) Which of the observed factors are associated with the use of involuntary treatment? 3) Who requests the use of involuntary treatment and who applies it? 


\section{Methods}

\subsection{Design}

A cross-sectional survey was conducted in the eastern part of Belgium. Data were collected from April to July 2017.

\subsection{Study setting}

The study was conducted in a home nursing organization that provides professional nursing care at home, in the eastern part of Belgium. The home nursing organization comprises 28 regional nursing departments. A regional nursing department comprises 20-27 districts. The number of patients in each regional department and district were approximately equal. Every district has a team, comprised of a responsible district nurse, assisted by permanent district nurses to ensure 24/7 care continuity. In Belgium, district nurses are mostly registered nurses with a bachelor's degree or an associate degree (Scheepmans et al., 2014). The district team is responsible for planning, coordinating, performing and evaluating the care in their district.

\subsection{Sample}

The participants of this study were older adults who met the following inclusion criteria: 1 ) being 60 years or older; 2) having a cognitive impairment, defined as having a score of 2 or more on the items disorientation in time and place of the Weckx scale (Lepeleire et al., 2005) 3) living at home; and 4) receiving professional nursing care at home. In this study the older adult could have a cognitive impairment due to several reasons, such as diagnosis of dementia, cardiovascular problems, brain tumour, stroke, alcohol or drug addiction. Exclusion criterion was: living in a residential care setting. In March 2017, the home health-care organization had 15,316 persons in care. A total of 4065 of them met the inclusion criteria. Based on a sample size calculation with an assumed prevalence rate of between 30 and $40 \%$ (Hamers et al., 2016), a 95\% confidence interval (CI) and a half width of 0.3 , a sample size of 1200 older adults receiving home care was calculated. Because a 10 per cent non-response rate was expected, 1344 older adults were needed. The older adults were selected from the existing database of the home health-care organization. In order to distribute the workload of the research across the 28 regional departments, the 1344 older adults were evenly distributed over the regional departments. The participants were then randomly selected per regional department using Microsoft Excel ${ }^{\bullet}$.

\subsection{Data collection}

In total, 578 responsible district nurses were asked to complete a questionnaire, using the online tool SurveyMonkey ${ }^{\circ}$, for each selected older adult in their caseload. The average number of questionnaires per district nurse was $2.3(\mathrm{SD}=1.3)$.

The procedure was as follows: 1) Before the start of the data collection, the district nurses and their head nurses were informed about the study by the principal researcher (VM) during meetings and by email; 2) All information (manual, example questionnaire, information letters, frequently asked questions, list of the included patients per department) about the research was shared using an online platform; 3) To complete the questionnaire, the responsible district nurse used information from the patient records and information received from the district team during weekly meetings; 4) To help the nurses fill in the questionnaire, there was a manual. In this manual, each question and measure of involuntary care was in detail described. If the measure that was applied matched the description in the manual, the nurse indicated this; 5) On the list per department, the district nurse recorded when a questionnaire was filled in or the reason when it could not be filled in. All lists of completed questionnaires vis-à-vis target sample size were
Table 1

Use of involuntary treatment in older adults receiving nursing care at home.

\begin{tabular}{|c|c|c|}
\hline Types of Involuntary Treatment & $\begin{array}{l}\text { Number of } \\
\text { measures }^{1}\end{array}$ & $\%(\mathrm{n}=625)^{2}$ \\
\hline \multicolumn{3}{|l|}{ Physical restraints } \\
\hline Waist belt in a (wheel)chair & 16 & 2.6 \\
\hline Waist belt in bed & 4 & 0.6 \\
\hline Wrist or ankle ties & 1 & 0.2 \\
\hline Chair with fixed tray table & 22 & 3.5 \\
\hline Deep, overturned, or reclined chair ${ }^{\mathrm{a}}$ & 27 & 4.3 \\
\hline Measures to prevent leaving the chair ${ }^{b}$ & 47 & 7.5 \\
\hline Locked (wheel)chair & 78 & 12.5 \\
\hline Bilateral fully enclosed bedrails ${ }^{c}$ & 183 & 29.3 \\
\hline Special sheet ${ }^{\mathrm{d}}$ & 6 & 1.0 \\
\hline Sleep suit ${ }^{\mathrm{e}}$ & 2 & 0.3 \\
\hline Restraint vest & 1 & 0.2 \\
\hline Gloves $^{\mathrm{f}}$ & 49 & 7.8 \\
\hline \multicolumn{3}{|l|}{ Psychotropic medication } \\
\hline Antidepressants & 163 & 26.1 \\
\hline Anti-epileptic & 29 & 4.6 \\
\hline Anti-psychotics & 80 & 12.8 \\
\hline Anxiolytics & 42 & 6.7 \\
\hline Hypnotics - sedatives & 101 & 16.2 \\
\hline \multicolumn{3}{|l|}{ Non-consensual care } \\
\hline $\begin{array}{l}\text { Forced or camouflaged medication } \\
\quad \text { administration }\end{array}$ & 57 & 9.1 \\
\hline Hiding medication $^{g}$ & 160 & 25.6 \\
\hline Forced food or fluid intake & 40 & 6.4 \\
\hline Forced hygiene $\mathrm{e}^{\mathrm{h}}$ & 173 & 27.7 \\
\hline Restricting communication ${ }^{\mathrm{i}}$ & 50 & 8.0 \\
\hline Locking older adult in house $\mathrm{e}^{\mathrm{j}}$ & 77 & 12.3 \\
\hline $\begin{array}{l}\text { Separation in another room without } \\
\text { locking }\end{array}$ & 164 & 26.2 \\
\hline Inappropriate clothing ${ }^{\mathrm{k}}$ & 17 & 2.7 \\
\hline Electronic supervision ${ }^{1}$ & 37 & 5.9 \\
\hline Shutting off gas or electricity ${ }^{\mathrm{m}}$ & 5 & 0.8 \\
\hline Restricting transportation ${ }^{\mathrm{n}}$ & 48 & 7.7 \\
\hline Removing walking aids & 3 & 0.5 \\
\hline
\end{tabular}

1 Multiple measures could be used with one older adult, so percentages do not add to 100 .

2 Percentage of the measures is calculated in relation to the 625 people who received involuntary treatment.

a Chair preventing from getting up.

b Chair with legs fixed on a board and setting chair against table to prevent leaving it.

c Bilateral fully enclosed bedrails and placing the bed against the wall to prevent leaving it.

d Fitted sheet including a cover enclosing the mattress to prevent leaving the bed independently.

e Clothing that prevents an older adult from self-undressing.

f Gloves that prevent an older adult from picking up objects.

g Hiding away all types of medication to prevent access to own medication.

$\mathrm{h}$ Forced hygiene or restraint during hygienic care.

i For instance, taking away telephone, hiding mail, restricting visitors, cutting off access to Internet.

$\mathrm{j}$ Locking all doors from the house or room to prevent leaving it.

${ }^{\mathrm{k}}$ For instance, not dressing an older adult to prevent them leaving the house, reversing a belt or trouser to prevent an older adult undressing them self.

${ }^{1}$ For instance, personal alarms, sensors and surveillance cameras.

$\mathrm{m}$ To prevent, for instance, cooking, heating stove, or microwave oven.

${ }^{\mathrm{n}}$ For instance, taking away car keys, inactivating car or bike.

integrated into a general online overview of the state of affairs; 6) By weekly checking, this overview and the database of the online survey tool, the principal researcher (VM) could monitor the progression of the survey, 6 ) If the progression of the survey was not according to schedule, the researcher contacted the head nurse and discussed actions for improvement.

The district nurses had 10 weeks to complete the questionnaires. No incentives were given to the district nurses for filling in the questionnaires. When the responsible district nurse of the selected patient 
could not complete the questionnaire, due to sickness, vacation or other reasons, another district nurse of the district team who knew the older adult completed the questionnaire.

\subsection{Measurements}

\subsubsection{Involuntary treatment}

The primary outcome of the study was involuntary treatment, including physical restraints, psychotropic medication, and non-consensual care. Our questionnaire is based on the questionnaire that was developed by Hamers et al. (2016). Table 1 presents the measures that were included in this study. The measures regarding physical restraint were based on the definition of Bleijlevens et al. (2016). For psychotropic drugs, a detailed list was composed in collaboration with a pharmacist based on the Anatomical Therapeutic Chemical Classification of the drugs that are prescribed in Belgium. Using this list, the nurse reviewed the medication list in the patient records to determine whether psychotropic medication was used, and if so, which kind. In our study we included psychotropic drugs as measures of involuntary treatment, for the following reasons: 1) older adults are vulnerable to adverse effects of psychotropic medication (e.g. memory impairment, psychomotor slowing, delirium, falls with a risk of hip fracture, psychiatric hospitalization); 2) there is little evidence of the effectiveness of psychotropic drugs in relation to the reasons they are used among older adults; 3) studies indicate that psychological well-being of the older adult is not the principal reason that psychotropic drugs are prescribed (Voyer et al., 2004). Due to practical reasons, only the appropriateness for antipsychotic medication was determined. If the older adult had a formal diagnosis of delirium, schizophrenia and/or psychosis, the use of antipsychotics was recorded as appropriate (Halfens et al., 2016). The measures regarding non-consensual care were based, on the measures used in the study of Hamers et al. (2016), it concerns measures that limit the organization of a person's own life and to which a person resists to.

Involuntary treatment that included at least one measure as described above, and that was used at least once during the previous 30 days, was recorded as absent (0) or present (1).

Finally, the persons who asked and applied involuntary treatment were recorded. These persons are listed in Table 2.

A category labelled 'other' was added for each question, allowing the district nurses to list additional measures or persons. Multiple answers were possible for all the above questions.

\subsubsection{Associated factors}

The sociodemographic characteristics gathered in this study

Table 2

Persons involved with the request and application of involuntary treatment in older adults receiving nursing care at home.

\begin{tabular}{|c|c|c|}
\hline Person & $\begin{array}{l}\text { Request }^{\mathrm{a}} \\
\mathrm{n}(\%)\end{array}$ & $\begin{array}{l}\text { Application }^{\mathrm{a}} \\
\mathrm{n}(\%)\end{array}$ \\
\hline Older adult & $69(11)$ & \\
\hline Informal caregiver & $443(71)$ & $416(67)$ \\
\hline Nurse/nursing aide & $271(43)$ & $504(81)$ \\
\hline Domestic aide & $29(5)$ & $33(5)$ \\
\hline General practitioner & $292(47)$ & $86(14)$ \\
\hline Physician specialist & $25(4)$ & $23(4)$ \\
\hline Physiotherapist & $13(2)$ & \\
\hline Occupational therapist & $1(0)$ & \\
\hline Social worker & $12(2)$ & \\
\hline Neighbour & $2(0)$ & \\
\hline I do not know & $15(2)$ & $7(1)$ \\
\hline
\end{tabular}

${ }^{\text {a }}$ Multiple persons could be involved in by the request and application of involuntary treatment by with one person, therefore percentages do not add up to $100 \%$ and so more than 625 persons were involved in the request or application of involuntary treatment. population were gender, age in years and living situation (alone or not alone).

To assess functional dependency and cognitive ability, two subscales (Activity of Daily Living Hierarchy (ADL-H) and Cognitive Performance Scale (CPS)) from the Inter Resident Assessment Instrument Home Care Belgium (InterRAI HC) (FOD Volksgezondheid Veiligheid van de Voedselketen en Leefmilieu, 2016) were used.

ADL-H Scale measures the ADL performance and classifies ADL performance according to the stages at which they can no longer be performed. Based on four ADL items (i.e. personal hygiene, toilet use, mobility, and eating), an algorithm was used to compute a 7-point scale, ranging from independent (0) to totally dependent (6) (Morris et al., 1999).

The Cognitive Performance Scale (CPS) has a predictive algorithm based on a decision tree. It used four items: short-term memory; decision-making; expression; and self-performance in eating. The result was a 7-point scale where scores ranged from intact (0) to very severely impaired (6) (Morris et al., 2016).

In order to determine whether the older adult had a formal diagnosis of dementia or not, the district nurse checked the patient record to see whether a physician (for example a general practitioner or psychiatrist) had determined the diagnosis of dementia.

Finally, to assess informal caregiver burden we used the SelfPerceived Pressure from Informal Care Scale (SPPIC) (range 0-9). A high score indicates a higher perceived informal caregiver burden (Pot, 2017). In the context of standard data collection to determine care goals, this scale had already been filled in by the informal caregiver and this information was therefore available in the patient record.

\subsection{Ethical approval}

The Social and Societal Ethics Committee, one of the Medical Ethics Committees of the Leuven University Hospitals approved the study protocol on 23 February 2017 (G- 201703 794).

\subsection{Data analysis}

To describe the prevalence of involuntary treatments and who requested and applied it, a descriptive analysis was conducted. Continuous data were expressed in means and standard deviations (SD). Categorical data were expressed in percentages. Percentages were calculated based on the actual number of answers. The prevalence of involuntary treatments was calculated by adding up the scores of all individual measures. If the older adult received at least one measure of involuntary treatment, they scored present (1); if no measures were used they scored absent (0). This was also done for the prevalence of physical restraints, psychotropic medication and non-consensual care.

To compare the characteristics of persons with and without involuntary treatment, independent-sample t-tests were used for the continuous variables (age, ADL-H, SPPIC, CPS-score) and chi-square tests for categorical variables (gender, living situation and diagnosis of dementia). Two-tailed tests with a significance of $\mathrm{P}<0.05$ were used. If there was no informal caregiver present, the question regarding informal care pressure (SPPIC-score) was omitted. If the SPPIC-score was missing, pairwise deletion was used for handling this missing data. The other questions were drafted in such a way that no questions could be omitted and so missing data were prevented.

To gain insight into the associated factors a random intercept logistic regression with regional departments as a second level random factor was conducted. This method was used to correct regional department differences. (Snijders and Bosker, 2012). All associated factors (age, CPS-score, ADL-H, SPPIC, gender, living situation and diagnosis of dementia) were included as independent variables and the application of at least one measure of involuntary treatment (present, absent) as the dependent variable. A backward procedure was performed. Factors with $\mathrm{P}>.10$ were removed one by one, with the least contributing 


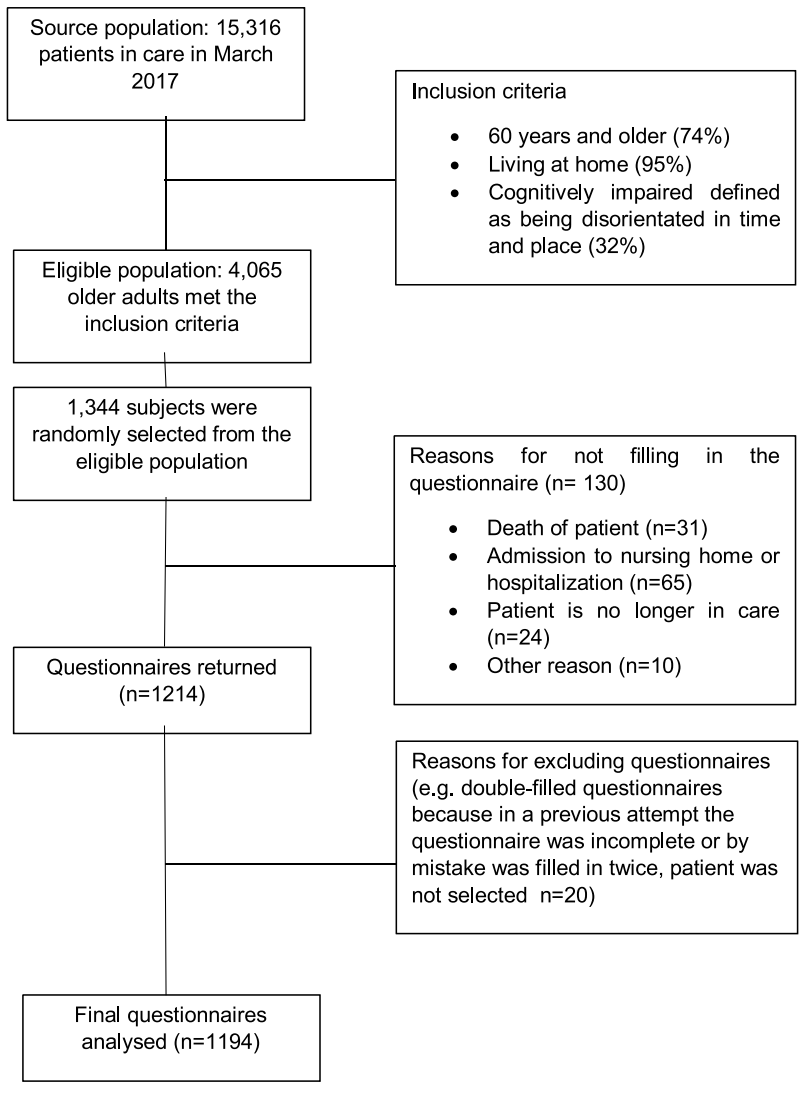

Fig. 1. Study flowchart.

factor being removed first. The significance of each estimated model parameter was tested with a significance level of $p<0.05$. We used SPSS, version 24 (SPSS, Inc., Chicago, IL).

\section{Results}

\subsection{Sample}

Fig. 1 shows that a total of 1344 older adults were selected for this study and for each of them a questionnaires had to be filled in. A total of 130 questionnaires were not returned due to various reasons and 20 were excluded. All other questionnaires $(n=1194)$ were included for analysis. The majority of the older adults were women $(67 \%, n=798)$; mean age was 83 years (SD 7.9). For 74 (6\%) older adults, there was no informal caregiver present. Table 3 shows the characteristics for the whole sample and for the two groups older adults receiving and not receiving involuntary treatment.

\subsection{Involuntary treatment}

In total, 1682 individual measures of some type of involuntary treatment were used in 625 older adults $(52 \%$, confidence interval $(\mathrm{CI})=0.49-0.55)$ of the total sample. Table 1 provides an overview of all involuntary treatment measures used. Most often (38\%), one measure of involuntary treatment was used. In $24 \%$ of the cases two measures were used, followed by four or more $(20 \%)$, and lastly, three (18\%) individual measures.

In $52 \%$ of the total sample $(n=625)$ one or more involuntary treatment measures were applied. In 240 out of those 625 persons (38\%, 95\% CI $=0.35-0.42)$ a physical restraint measure was used. In 115 older adults, two or more different physical restraints were used. In total, 270 older adults $(43 \%, 95 \% \mathrm{CI}=0.39-0.47)$ received some type of psychotropic drugs. In 101 older adults, two to three different types of psychotropic drugs were used. In 1 older adult five different types of psychotropic drugs were used. In 22 of 80 older adults $(27.5 \%)$ who received anti-psychotic drugs there was no diagnosis of schizophrenia, delirium or psychosis. In total, 831 measures of non-consensual care were used in 457 older adults (73\%, $95 \mathrm{CI}=0.70-0.77)$. In 195 older adults, two to four and in 17 older adults five or more different measures of non-consensual care were used.

\subsection{Factors associated with involuntary treatment}

Table 3 shows the results of the unadjusted analyses. Involuntary treatment was more likely to be applied with persons who were of a younger age, formally diagnosed with dementia, lived together and had a poorer cognitive ability, higher ADL-dependency and an informal caregiver who perceived a higher burden. Table 4 shows the result of random intercept logistic regression with regional departments as a second level random factor. The risk of involuntary treatment increases with a greater informal caregiver burden, poorer cognitive ability, higher ADL dependency and younger age.

\subsection{Request and application of involuntary treatment}

Table 2 shows an overview of who requests and who applies involuntary treatment. Of the 625 older adults who received involuntary treatment, the informal caregiver most frequently asked for the use of involuntary treatment followed by the general practitioner and district nurse.

District nurses mostly applied the involuntary treatment, followed by informal caregivers. Frequently applied measures by informal caregivers were bedrails and placing the bed against the wall (48\%; $\mathrm{n}=202)$, for district nurses $(43 \% ; \mathrm{n}=217)$ and general practitioners $(72 \% ; n=62)$ this was giving psychotropic medication. Also, district

Table 3

Sample characteristics according to involuntary treatment use in older adults receiving nursing care at home.

\begin{tabular}{|c|c|c|c|c|}
\hline & Overall $=1194$ & $\begin{array}{l}\text { Older adults without involuntary treatment } \\
\mathrm{n}=569(47.7 \%)\end{array}$ & $\begin{array}{l}\text { Older adults with involuntary treatment } \\
\mathrm{n}=625(52.3 \%)\end{array}$ & p-value \\
\hline Mean age (SD) & $82.5(7.9)$ & $83(7.4)$ & $82(8.4)$ & $\mathrm{p}=0.034$ \\
\hline Female, $\mathrm{n}(\%)$ & $798(67)$ & $381(67)$ & $417(67)$ & $\mathrm{p}=0.930$ \\
\hline Living alone, n (\%) & $501(42)$ & 278 (49) & $223(36)$ & $\mathrm{p}<0.001$ \\
\hline Dementia diagnosis, $\mathrm{n}(\%)^{\mathrm{a}}$ & $217(18)$ & $69(12)$ & $148(24)$ & $\mathrm{p}<0.001$ \\
\hline Cognitive Performance score, mean (SD) (range 0-6) & $2.5(1.7)$ & $2.0(1.4)$ & $3.1(1.7)$ & $\mathrm{p}<0.001$ \\
\hline Activity of Living-Hierarchy, mean (SD) (range $0-6)^{\mathrm{b}, \mathrm{c}}$ & $2.8(1.4)$ & $2.3(1.3)$ & $3.2(1.4)$ & $\mathrm{p}<0.001$ \\
\hline $\begin{array}{l}\text { Self-Perceived Pressure Informal Care scale burden), } \\
\text { mean (SD) (range 0-9) }\end{array}$ & $3.7(3.4)$ & $2.9(3.2)$ & $4.4(3.4)$ & $\mathrm{p}<0.001$ \\
\hline
\end{tabular}

$\mathrm{SD}=$ standard deviation.

a As recorded in the nursing records and confirmed by a medical doctor.

b Subscale of the Resident Assessment Instrument Home Care Belgium.

c Lower scores are more favourable. 
Table 4

Characteristics associated with involuntary treatment use in older adults receiving nursing care at home, a two-level logistic regression.

\begin{tabular}{|c|c|c|c|c|c|c|}
\hline \multirow[t]{2}{*}{ Variables in the Equation } & \multirow[t]{2}{*}{ Coefficient } & \multirow[t]{2}{*}{ Odds Ratio (OR) } & \multirow[t]{2}{*}{ Standard Error } & \multirow[t]{2}{*}{ P- value } & \multicolumn{2}{|c|}{ 95\% CI Odds Ratio } \\
\hline & & & & & Lower & Upper \\
\hline Diagnosis of dementia & 0.335 & 1.40 & 0.2 & $\mathrm{p}=0.094$ & 0.94 & 2.07 \\
\hline Cognitive Performance Scale score ${ }^{\mathrm{a}}$ & 0.332 & 1.39 & 0.054 & $\mathrm{p}<0.001$ & 1.25 & 1.55 \\
\hline Self-Perceived Pressure from informal care service & 0.053 & 1.05 & 0.022 & $\mathrm{p}=0.018$ & 1.01 & 1.10 \\
\hline Activity of Daily Living - Hierarchy ${ }^{\mathrm{a}}$ & 0.404 & 1.50 & 0.061 & $\mathrm{p}<0.001$ & 1.33 & 1.69 \\
\hline Age of the older adult & -0.032 & 0.97 & -3.41 & $\mathrm{p}=0.001$ & 0.95 & 0.99 \\
\hline
\end{tabular}

Intraclass Correlation Coefficient (ICC) $=0.21$.

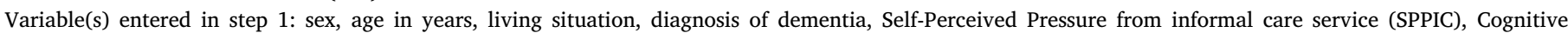
Performance Scale score (CPS), Activity of Daily Living - Hierarchy (ADLH).

Dependent variable is involuntary treatment: No $=0$, Yes $=1$.

a Subscale of the Resident Assessment Instrument Home Care Belgium.

nurses were mostly involved in preventing leaving the bed (35\%; $\mathrm{n}=179)$, hiding medication $(27 \% ; \mathrm{n}=138)$ and forced hygiene $(31 \%$; $\mathrm{n}=157)$.

\section{Discussion}

This study provided an insight into the use of involuntary treatment among older adults with cognitive impairment receiving nursing care at home, in Belgium. We found that one out of two older adults were subject to at least one measure of involuntary treatment. Factors that were associated with involuntary treatment were informal caregiver burden, ADL-dependency, cognition and age. Informal caregivers most often requested the use of involuntary treatment and the district nurse most often applied it.

The results of our study are in line with previous studies and confirm that involuntary treatment is commonly used in home care. However, the prevalence of involuntary treatment in our study seems to be higher compared to previous studies on home care (Beerens et al., 2014, Hamers et al., 2016; Scheepmans et al., 2017a). Comparing our study results with these studies is difficult, due to differences in the overall sample, health-care systems, culture, characteristics and method. The study by Hamers et al. (2016) found that involuntary treatment was used in $39 \%$ of older adults with a cognitive impairment who were followed up by dementia case managers. The study by Scheepmans et al. (2017a) found a prevalence of $24 \%$ among older adults receiving nursing care at home. In contrast with our study, no psychotropic medication and only a few measures of non-consensual care were included in this study. The European RightTimePlaceCare study (Beerens et al., 2014) found an overall prevalence of 55.9\% for the use of psychotropic medication (antipsychotics, anxiolytics, hypnotics/sedatives and antidepressants) and $9.9 \%$ for the use of physical restraints among persons with dementia receiving formal home care. But compared to our study, only four measures (belt restraints, locked chair/table, deep/overturned chair, bedrails) were included as physical restraint and anti-epileptic drugs were not included in this study.

In our study, factors strongly associated with involuntary treatment were higher ADL-dependency, poorer cognition and greater informal caregiver burden. This is in line with earlier research in home care and confirms that ADL-dependent older adults with a cognitive impairment living at home are at risk of involuntary treatment (Hamers et al., 2016; Scheepmans et al., 2017b; Hamers, 2005). This can be explained by the fact that measures of involuntary treatment are often used to safeguard older adults who are more ADL-dependent and cognitively impaired, from physical harm (De Veer et al., 2009). Therefore it is important that we can manage the neuropsychiatric symptoms (e.g. aggression, depression) associated with reduced cognitive ability. Research shows that a person-centered care approach can effectively reduce these symptoms and so prevent and reduce involuntary treatment. However this approach must go along with continuous training and education so that all caregivers are motivated to apply it (Kim and Park, 2017; Konno et al., 2014). Furthermore, the study Karlsson et al. (2015) shows that a trusting relationship, a single point of contact and individualized tailored-made care plan are also key-elements to support cognitive impaired older adults and their informal caregivers.

In agreement with earlier studies, we found that informal caregivers played the most crucial role in requesting involuntary treatment (De Veer et al., 2009; Hamers et al., 2016; Scheepmans et al., 2017a). One reason for this could be that they sometimes experience delivering care as a situation of enduring stress and frustration (Etters et al., 2008). Whenever their situation becomes hopeless, they look for solutions to handle this situation. Due to their lack of knowledge of the negative impact of involuntary treatment and adequate care, they often choose it (Kurata and Ojima, 2014). An additional problem is that informal caregivers are not authorized to apply most of the measures of involuntary treatment (e.g. physical restraints), according to Belgian legislation. In contrast with a previous study (Scheepmans et al., 2017a), we found a greater involvement of the general practitioner in the request for involuntary treatment. This could be explained by the fact that the general practitioner might focus on the prevention of the informal caregiver's burden and therefore support the request of the informal caregiver for involuntary treatment, or the general practitioner suggests it. The fact that psychotropic drugs were included in this study, and that these must be prescribed by a general practitioner, could also explain a greater involvement of the general practitioner. The Belgian legislation in combination with the fact that receiving nursing care at home was an inclusion criterion could explain the high involvement of the district nurses in the application of involuntary treatment. In Belgium, only registered nurses or general practitioners are authorized to apply most of the measures (e.g. physical restraints, psychotropic medication) that we included as involuntary treatment.

The results of the current study demonstrate that there were several factors associated with the use of involuntary treatment and different caregivers were involved in the request and application of it. For these reasons, we need an approach that is multifactorial. Several studies (Lan et al., 2017; Gulpers et al., 2011) indicate that a multifactorial approach with the following components: policy, education, consultation and alternatives is effective to reduce physical restraint in nursing homes. Because, if caregivers have the skills and knowledge about alternative methods to protect older adults from harm, there is no reason to apply measures that hurt them (Lan et al., 2017). At this moment there are no such studies known in home care. That's why we need to gain more insight into the effect and feasibility of multifactorial approaches to prevent and reduce involuntary treatment at home.

One of the strengths of the current study is the inclusion of a large randomized sample of 1194 older adults and the high response rate (89\%). Therefore, it can be assumed that we have a representative sample of our study population and the risk of selection bias is low. The high response rate (see Fig. 1) demonstrates an accurately performed 
data collection. However, there are also limitations that need to be mentioned: first, the research was conducted in only one region of Belgium, in which the average ADL-dependency was higher compared to the rest of Belgium (Cloots et al., 2017) and therefore one must be careful generalizing these results. Nonetheless, this study showed that ADL-dependency is strongly related to involuntary treatment. Therefore, it is logical that in a region and regional departments where there is a higher level of ADL-dependency, the prevalence of involuntary treatment will be higher. This fact might also explain the existing variability in the use of involuntary treatment between the regional departments in our study. Furthermore, one can argue whether the measures that are reported should be considered as involuntary treatment or not. In some cases, certain measures do not always have a negative effect and can even increase the freedom of the older adult. For instance, electronic mobile supervision system can reduce the fear of falling and thereby increase the mobility of the older adult. However, involuntary treatment has a negative impact on the quality of life and these examples do not legitimize their automatic use to all older adults in our sample (Hamers et al., 2016). In contrast to the use and effects of physical restraints, little is known about the use and effect of nonconsensual care. We agree that some measures that are listed in Table 1 could be in certain conditions appropriate care. However, if a patient openly resists to care and therefore become aggressive, because no proper alternative is provided one can discuss its safety and comfort (Konno et al., 2014). Furthermore, caregivers are not always aware that they are providing non-consensual care and appropriate alternatives exist, due to a lack of knowledge. For these reasons, we choose a broad interpretation of the concept of non-consensual care, in order to get sufficient insight into the use of involuntary treatment. Our study found that is the most common form of involuntary treatment. Therefore, further studies should especially focus on the consequences of nonconsensual care for the patient and his caregivers. Finally, we included a broad range of psychotropic drugs as involuntary treatment. Although psychotropic drugs are often inappropriate for older adults living at home (Voyer et al., 2004), in certain cases they could be appropriate. In our study, three out of four older adults received anti-psychotic drugs in the treatment of delirium, schizophrenia or psychosis. As not all psychotropic medication that was included in our study might have been inappropriate, because it was needed for treatment, this could increase the risk of an overestimating of the prevalence of involuntary treatment in our study. However, in $70 \%$ of the cases, psychotropic medication was combined with other measures of involuntary treatment. Therefore, it is unlikely that this led to a large overestimation of the prevalence of involuntary treatment.

In conclusion, this cross-sectional study provides more insight into the use of involuntary treatment. We demonstrated that it is common among older adults with a cognitive impairment receiving nursing care at home. The implication of this study for clinical practice is that it confirms the need to develop an approach to prevent and reduce the use of involuntary treatment. Therefore, this information is valuable for nurses and other caregivers who focus on patient-centred care. Further research is needed to plan and develop an approach to change the behaviour of the caregivers involved, in order to prevent and reduce the use of involuntary treatment.

\section{Conflict of interest}

None declared.

\section{Funding}

No external source of funding.

\section{Acknowledgments}

We thank the participating district nurses, head nurses and staff of the White Yellow Cross Limburg, in Belgium.

\section{References}

Beerens, H.C., Sutcliffe, C., Renom-Guiteras, A., Soto, M.E., Suhonen, R., Zabalegui, A., Bökberg, C., Saks, K., Hamers, J.P., Consortium, R., 2014. Quality of life and quality of care for people with dementia receiving long term institutional care or professional home care: the European Right Time Place Care study. J. Am. Med. Dir. Assoc. 15, 54-61.

Bleijlevens, M.H., Wagner, L.M., Capezuti, E., Hamers, J.P., 2016. Physical restraints: consensus of a research definition using a modified Delphi technique. J. Am. Geriatr. Soc. 64, 2307-2310.

Brodtkorb, K., Skisland, A.V.-S., Slettebø, ̊., Skaar, R., 2015. Ethical challenges in care for older patients who resist help. Nurs. Ethics 22, 631-641.

Cloots, H., De Kind, H., Smets, H., 2017. In: Gezondheid, A.Z.E. (Ed.), Zorgzwaarte in de thuisverpleging. Vlaamse overheid, Brussel.

De Veer, A.J., Francke, A.L., Buijse, R., Friele, R.D., 2009. The use of physical restraints in home care in the Netherlands. J. Am. Geriatr. Soc. 57, 1881-1886.

Etters, L., Goodall, D., Harrison, B.E., 2008. Caregiver burden among dementia patient caregivers: a review of the literature. J. Am. Acad. Nurse Pract. 20, 423-428.

FOD Volksgezondheid Veiligheid van de Voedselketen en Leefmilieu, 2016. BelRAI - Een uniforme en web based (online) registratie van interRAI-beoordelingsinstrumenten. [Online]. Brussel. Available:. (Accessed 19 November 2016).. https://www.ehealth. fgov.be/nl/application/applications/BELRAI.html.

Gastmans, C., Milisen, K., 2006. Use of physical restraint in nursing homes: clinicalethical considerations. J. Med. Ethics 32, 148-152.

Gjerberg, E., Hem, M.H., Førde, R., Pedersen, R., 2013. How to avoid and prevent coercion in nursing homes: a qualitative study. Nurs. Ethics 0969733012473012.

Gulpers, M.J., Bleijlevens, M.H., Ambergen, T., Capezuti, E., Rossum, E., Hamers, J.P., 2011. Belt restraint reduction in nursing homes: effects of a multicomponent intervention program. J. Am. Geriatr. Soc. 59, 2029-2036.

Halfens, R., Meijers, R.J.G., Meesterberends, E., Neyens, J., Rondas, A.A.L.M., Rijcke, S., Wolters, S., Schols, J.M.G.A., 2016. Landelijke prevalentiemeting zorgproblemen: rapportage resultaten 2015. Universiteit Maastricht, Maastricht.

Hamers, F.J., 2005. Why do we use physical restraints in the elderly? Z. Gerontol. Geriatr. $38,19-25$

Hamers, J.P., Bleijlevens, M.H., Gulpers, M.J., Verbeek, H., 2016. Behind closed doors: involuntary treatment in care of persons with cognitive impairment at home in the Netherlands. J. Am. Geriatr. Soc. 64, 354-358.

Hofmann, H., Hahn, S., 2014. Characteristics of nursing home residents and physical restraint: a systematic literature review. J. Clin. Nurs. 23, 3012-3024.

Joseph-Williams, N., Elwyn, G., Edwards, A., 2014. Knowledge is not power for patients: a systematic review and thematic synthesis of patient-reported barriers and facilitators to shared decision making. Patient Educ. Couns. 94, 291-309.

Karlsson, S., Bleijlevens, M., Roe, B., Saks, K., Martin, M.S., Stephan, A., Suhonen, R. Zabalegui, A., Hallberg, I.R., 2015. Dementia care in European countries, from the perspective of people with dementia and their caregivers. J. Adv. Nurs. 71, 1405-1416.

Kim, S.K., Park, M., 2017. Effectiveness of person-centered care on people with dementia: a systematic review and meta-analysis. Clin. Interv. Aging 12, 381.

Koller, D., Schön, G., Schäfer, I., Glaeske, G., Van Den Bussche, H., Hansen, H., 2014 Multimorbidity and long-term care dependency-a five-year follow-up. BMC Geriatr. $14,70$.

Konno, R., Kang, H.S., Makimoto, K., 2014. A best-evidence review of intervention studies for minimizing resistance-to-care behaviours for older adults with dementia in nursing homes. J. Adv. Nurs. 70, 2167-2180.

Kurata, S., Ojima, T., 2014. Knowledge, perceptions, and experiences of family caregivers and home care providers of physical restraint use with home-dwelling elders: a crosssectional study in Japan. BMC Geriatr. 14, 1.

Lach, H.W., Chang, Y.-P., 2007. Caregiver perspectives on safety in home dementia care. West. J. Nurs. Res. 29, 993-1014.

Lan, S.-H., Lu, L.-C., Lan, S.-J., Chen, J.-C., Wu, W.-J., Chang, S.-P., Lin, L.-Y., 2017 Educational intervention on physical restraint use in long-term care facilities-systematic review and meta-analysis. Kaohsiung J. Med. Sci. 33, 411-421.

Lepeleire, J., Paquay, L., Jacobs, M., 2005. De verschillende schalen voor ADL-activiteiten voor volwassen in de Vlaamse gezondheidszorg. Huisarts Nu 34, 11.

Morris, J.N., Fries, B.E., Morris, S.A., 1999. Scaling ADLs within the MDS. J. Gerontol. A: Biol. Sci. Med. Sci. 54, M546-M553.

Morris, J.N., Howard, E.P., Steel, K., Perlman, C., Fries, B.E., Garms-Homolová, V., Henrard, J.-C., Hirdes, J.P., Ljunggren, G., Gray, L., 2016. Updating the cognitive performance scale. J. Geriatr. Psychiatry Neurol. 29, 47-55.

Pijl-Zieber, E., Hagen, B., Armstrong-Esther, C., Hall, B., Akins, L., Stingl, M., 2008. Moral distress: an emerging problem for nurses in long-term care? Qual. Ageing Older Adults 9, 39-48.

Pot, A., 2017. Family Caregiving to Older Adults (Side Study) Self-Perceived Pressure from Informal Burden. [Online]. Available:. (Accessed). http://www.lasa-vu.nl/ themes/care/burden-informal-caregiver htm.

Scheepmans, K., De Casterlé, B.D., Paquay, L., Van Gansbeke, H., Boonen, S., Milisen, K., 2014. Restraint use in home care: a qualitative study from a nursing perspective. BMC Geriatr. 14, 17.

Scheepmans, K., Dierckx De Casterlé, B., Paquay, L., Van Gansbeke, H., Milisen, K., 2017a. Restraint use in older adults receiving home care. J. Am. Geriatr. Soc. 65 (8), 1769-1776.

Scheepmans, K., Dierckx De Casterlé, B., Vanbrabant, K., Paquay, L., Van Gansbeke, H., Milisen, K., 2017b. Associated Risk Factors of Restraint Use in Older Adults with 
Home Care.

Snijders, T., Bosker, R., 2012. Multilevel Analysis. An Introduction to Basic and Advanced Multilevel Modeling, 2nd edition. Sage, Los Angeles.

Stubbs, B., Brefka, S., Denkinger, M.D., 2015. What works to prevent falls in communitydwelling older adults? Umbrella review of meta-analyses of randomized controlled trials. Phys. Ther. 95, 1095-1110.

Voyer, P., Cohen, D., Lauzon, S., Collin, J., 2004. Factors associated with psychotropic drug use among community-dwelling older persons: a review of empirical studies.
BMC Nurs. 3, 1.

Wet van 24 januari 2018, houdende regels voor het kunnen verlenen van verplichte zorg aan een persoon met een psychische stoornis (Wet verplichte geestelijke gezondheidszorg).

Wickremsinhe, M.N., 2018. Emergency involuntary treatment law for people with mental disorders: a comparative analysis of legislation in LMICs. Int. J. Law Psychiatry 56, 1-9. 